ARTIGOS

E

ENSAIOS 


\section{A ÉTICA DE LEIBNIZ}

Fentando Tadeu Ribeiro Do Val *

\section{Resumo:}

A razăo a vontade dirigem a felicidade. Leibniz professa um idealismo meional, marcando a reflexão consciente dos lins e das leis de uma vida racional. A felicidade năo pode prescindir do instrumento da razão. $A$ lei moral quer que o homem cumpra sua obra de ser inteligente e livre, seguindo a fazz̃o. A consciência matal é a expressāo de um julgamento racional que dirige as ações. Segundo Leibniz a razão de nossas açōes está ent nós mesmos e somente o homem possui a rellexăo consciente.

A ravă a dominar o espirito, liberta a vortade, ano inves de restringi-la. Leibniz professa que a vontade se identifica com aquela energia viva e ativa que forma a substancin de rodo o ser oryanizado, constimindo sta individualiade. O ser moral depende do ser raciomat, escolhendo os melhores fins para atingir-se a perfeição e a felicidade. lsto implica em liberdade, live arbitrio. Para Leihnì a vontade do homen é livve e autonoma, näo violando as leis naturais, seguindo, pottanto, un determinismo universal. Por sua vez, a liberdade se fundamenta na subnissão relletida da Vontade à razăo.

\section{Palavras-chave:}

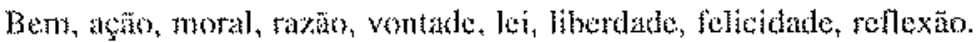

A razão exerce um papel direcionador sobre a vontade e a intervenção da reflexão, desse poder inerente à consciência humana de refletir sobre suás próprias impressòes, de conhecer a ordem e razão do seu encadeamento, de conceber a idéa ou a representacă geral das possibilidades da vida interior e das leis que a regem, confere ao homem o caráter es privilégios da personalidade eferece às açós um valor moral.

Será essa intervenção que transformará no homem a atividade primitiva e espontânea, opondo-a à atraçăo sensivel do prazer da satisfaçăo imediata e passageira, a concepçăo e o desejo de satikfações mais puras e duráveis, enfim, a idéía de felicidade, objeto soberano da vontade, quando dirigida pela fazío. Énquanto o sentimento o desejo direcionam ao prazer, a razäo e a vonkde conduzem à felicidade.

Igualmente distante do misticismo, reduto de crença cega, albergue de um ato de te na infalibilidade de uma consciência moral e do positivismo que busca nas

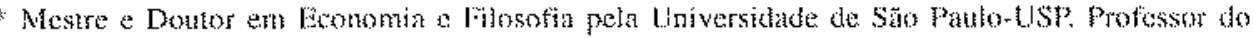

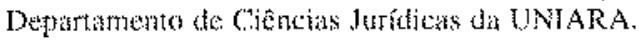




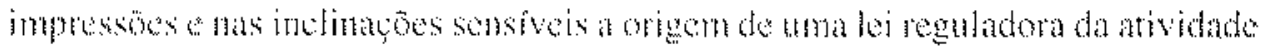

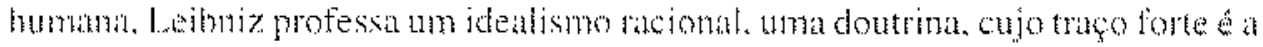

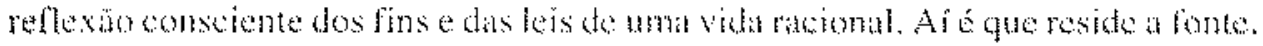

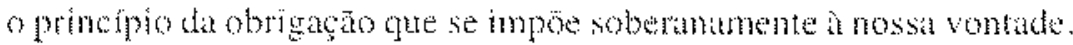

A felicidade näo somente tm grau superior e mas refinado de prazer porgute

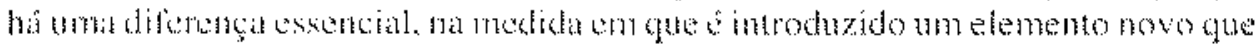

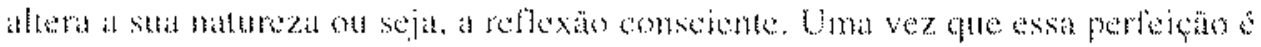
conquistada revela ov vor do ser em sut propria sssencia. Mats a felicidade e um

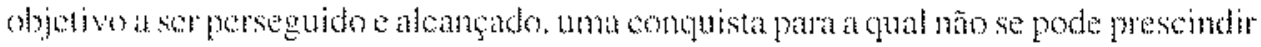

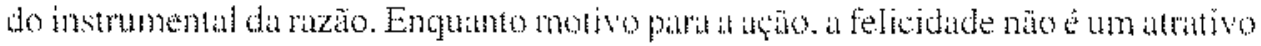

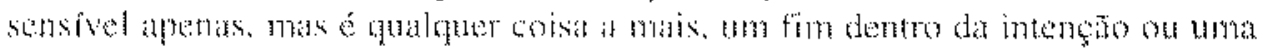

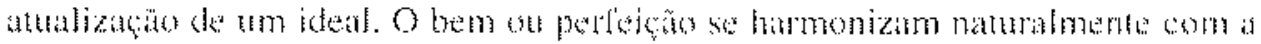
relicidade. Näo somente o ser. mas a propria natureza detentora de uma fimalidade imathente terdendo essencialmonts para o methor.

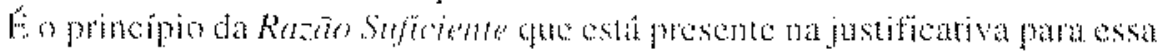

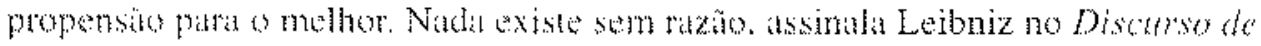

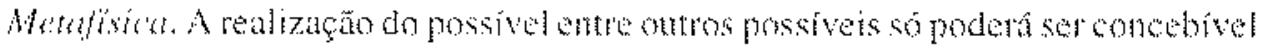

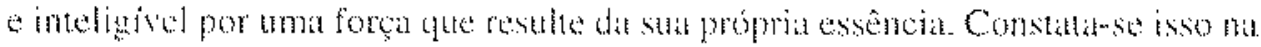

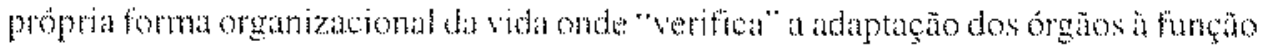

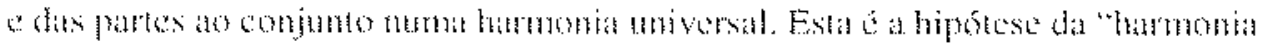

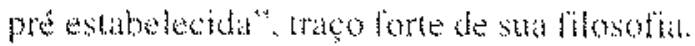

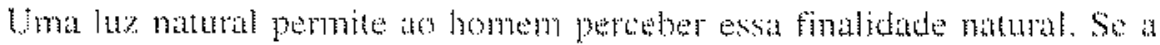

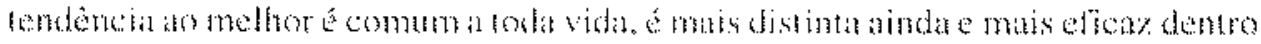

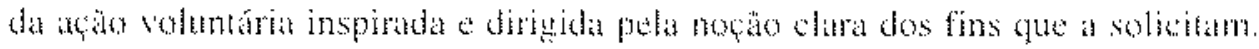
Dessa compreensato ampla da ordem unversal surge espontaneamente a doutrina motal. onde o conhecimento cientilico das las da natureza se alham a combepäo ideal de uma lei mais distintamente inteligfel a de uma ordem superior ande o

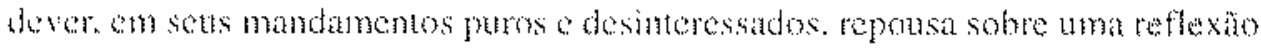

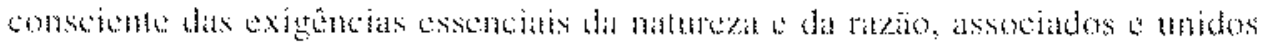
devatro do pensamento ed vontade, odevejo de ser feliz. Se a dourina aristoblica

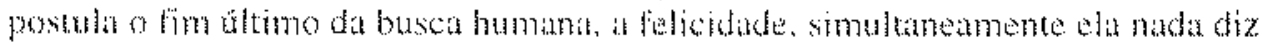

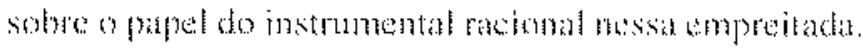

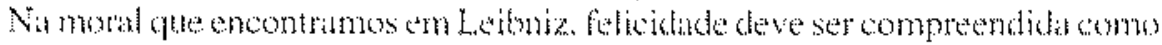

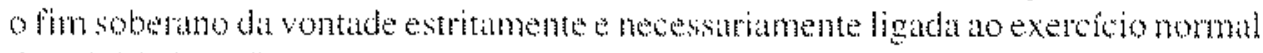
da atividade reflexiva. que buscara my otjeto a melhor, dentro de um progresso comthuc e imblinido rumo is perfeçitur.

A lei moral năo exige do homem rada mais do que a firmeza e a persevena cm cumprir dentro dos limites de suk lactdades. sua obra de ser inteligente elive segmdo o deal de perfeica sngeridi pelu moto a esolha dos diversos bens

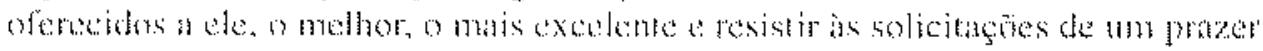

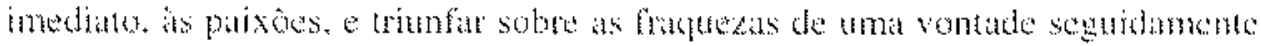


incerta em seu podor. Assim. dever se constitui em uma necessidade moral.

A recompensat assa sabedorat sa forgo sert a felicidade, um estado de alma. uma disposigato que se completa e repousa dentro da atividade hamonosa do suas faculdides en conformidude com uma lei ditintamente conbecida e deliberadamente acefta. E un proceder deal gue implica a noça dara das possibilidades gue se oferecem vontade o discemimento dos bens de natureza diversificada e de ponderacou do seta valor.

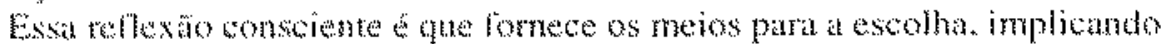
tambern o conhecimento aneincaio consciente da necessidade racional da disciphina

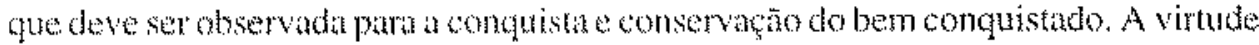
Eum derivativo da observância das regras de conduta na viơ.

A moraliode tem seu prifépio na esfera humana e conforne as leis naturais. A fonte da monalidade 6 a ordem matural a qual e transposta a uma ordem superior. O progresso que a homem at inge ha vida intima atesk tma riqueza intransponivel e

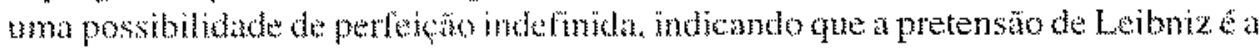
matematizaço da moralidade, adeguando chamonizando-a âs contingencias da vida.

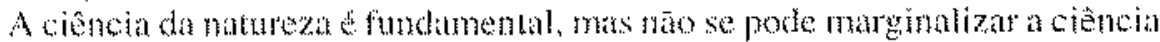

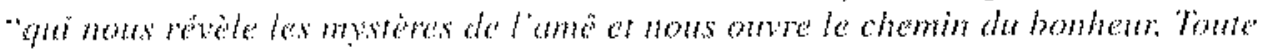

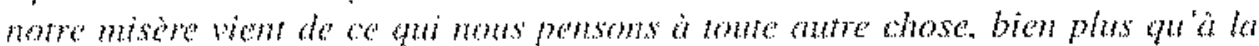

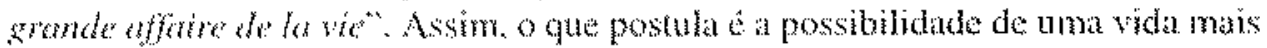
introspectiva, uma reflexär solye a vontade, uma travessia sobre o mundo, sobre seu Autot, elencando a felicidade como ofm úlime de todas as buscas.

Consciencia molal a a expressäo de um jugamento racional que tem ascendencia sobts o valor relativo das solicitaçöes que conduzem à açá É desisa expressabo gue se origina ma alma humana o pensmento e vontade de uma vida mais porfeita e mais feliz. so mesmo tempo que origina o sentimento da obrigaga ou

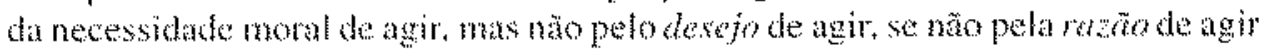
(aço depunada pela reflexiotol.

Uma das tases centats ma tilosofia de Leibniz é que não há vazio no universo. Eo Prinefipo do Continuo de divisibilidade infinita da matéta. Como a natureza

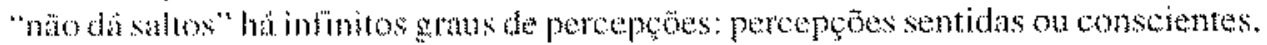
fugridas, antras lixadas e mantidas e aquelas que nāo săo sentidas ou inconscientes, pequenas percepes. As perepgose confusas decorrem da nossa incapocidade de identificar no complexo as parte diminutas ou simples. Conto as pereepoès da alma săo claras, ela tem dominio solme a compo, mas năo hä interação entre ambos.

A maiora das perepsoes vem dos óngäs internos na devidamente considerados, a menos gue sejam males. Como há algumas que sân percobidas fracamente e preciso atencia para observim, podendo-se comparí-las as unidades inlinitanyte pequenas, diminutas, cuja soma detcrminará um inteiro. Desempenham papel fundamental na vida mental, pois explicam nossos apetites, angüstas, antipathas e habitos de pensincmo comades insonscientemente. 
Assim, o que caracteriza in sha doutrina moral, o que the confere um valor cientifico é que ela nĩo tredu simplesmente urma aspiraça da alma, solictada por um ideal de perfeiço de folicidade. Ela deriva de una ordem universal, justiftada, cm biltima instancias sobre o conhecinento de leis raturas apticada a vida humana esclarecida e dirigida pela razo pela rellexa consente de ara finalidade de um conbermento dos the idalmente concebidos e de seu valor nativo, permindo nascer no homem opensamento a vontade do mexthor $O$ s sfore que ai se determina

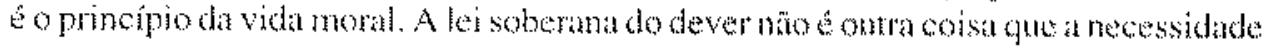

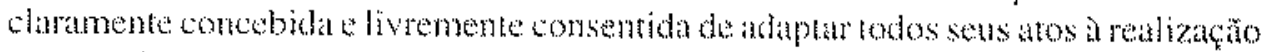

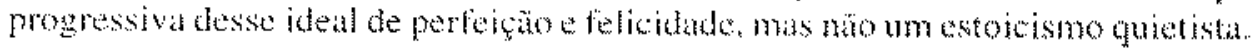

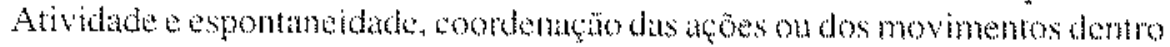
de uma ordem deteminala pelas exigências de um deservolvimento nomal das existencias naturats sio os elementos que se anem dentro da idáa de finalidade. A

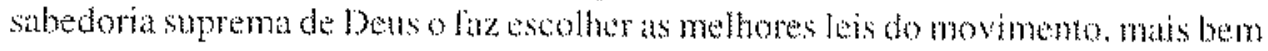

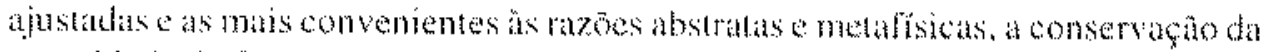

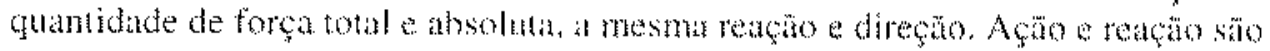

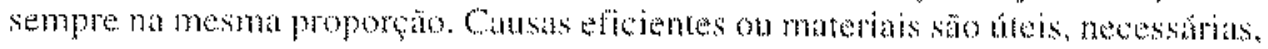
mas nāo sa suficiontes para explicar como se processam as mudancas, as leis do movimeno, como quer o meancismo cartesiano, mas insuficiertes para a räb. porque representa explica os movimentos, is acoes, como se apresentam ans nossos

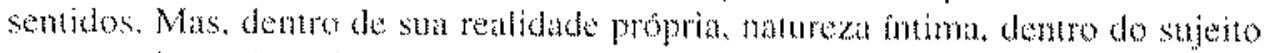
que a produz nada podemos conceber. exceto sob a forma e caracteristica de energia.

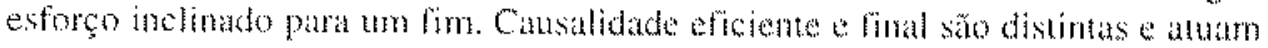
como se isoladamente nöo existisse, mas nio säo athonomas, porque isoladaneme nada podem explicar. Assim a poder de Deus esta por was das causas eficientes sua Sabedoria por ans do finalismo. Observeme que o que impora e o principio de

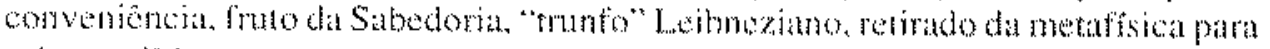
Salvar al fisicia.

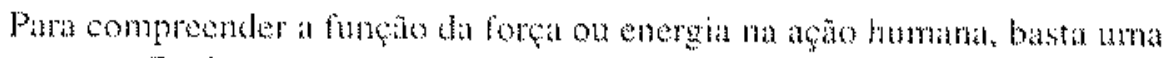

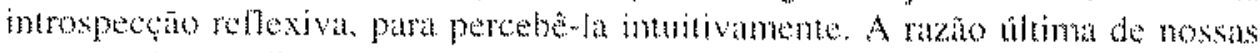
açoss, toda a realidade intima da matriz passional que no faz persegrit um fim. estäo em nos mesmos. Assim, como at mente humana laz pante desse univesto, da natureza mesma, a mesma linalidade, adaptaçä dos melos asos tins, a organizacto dos elementos naturais es armyos realizados para a consectąo de um objetivo

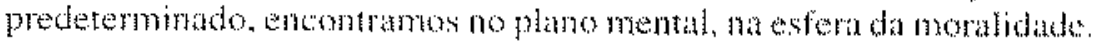

Uma va posta em aça a máquina, o feto que dar deve resular explica a maneira de sua concep̧īo, de sua existencha Restmindo of fim em vista do qual ela for construida a causa verdaduina de sta criacio. Analogamente, isto pode ser dito dos organismos naturais. Seguindo os fins, pode-se melhor conhecer os meios. Mas, a esponaneidade inerente a toda substancia näo exchu a sua autoria por Deus nem abre uma va de conflito entre nesessidade be liberdade moral. 
O hábito, mulas vezes, nos leva à açăo irrelletida e sem esforço, mas a mesmo tempo há inúmeras açỏes onde há uma intençäo prévia. É lógico atribuir uma certa consciência de uma finalidade, o sentimento de am objetivo a atingir, um conhecimento obscaro, mas efetivo, porque e suscetível de regular e dirigir os movimentos tha direça do objetivo.

Do concurso da hamonia de todas as atividades individuais, cuja espontaneidade obedece à lei comm da finalidade, resulta uma finalidade universal, sobre a qual repousa a ordem natural. Uma mesma tendência leva espontaneamente cada um dos seres particulares na direção da realizaçäo sempere mais completa da vida, a um crescimento continuo de uma força, à uma perfeição maior que sua natureza comporta.

A trama da vida interior é composta de impressöes, aleiçoes e ação, obscuramente conscientes e muitas vezes desapercebidas ou penscmentos surdos, sem a perepcato ou sem reflexão, sendo por esta va que o homem se aproxima dos animass seja porque tais sentimentos șo por demais reduzidos, seja porque săo de grande diversidade quantitativa. O habito desempenha papel de enome importancia neste processo. Somente de forma confusa estamos conscientes de sua presença na alma. É este o cerário de um dos estudos de inconsciência apontado por Leibniz. Essas perceperes reduzidas são mais eficazes do que se imagina, porque formam o gosto, imagens de qualidade dos sentidos, claras no conjanto, mas confusas isoladamente. São essas pereepços que ampliam a possibilidade de engano pelas aparências e conduzem ao erro por uma indiferença de equilibrio, como se fossemos indiferentes a virar à esquerda ou à dieita. Isso contradiz o cartesianismo que concebe as percepcós como arbitrárias, como se Deus as tivesse dado à alma aleatoriamente, sem ter em vista alguma relaçăo essencial entre as percepçoses e os objetos, o que seria pouco digno do Autor das coisas, porque faria tudo sem hamonia e razão.

Percepcos reduzidas formam o conjunto de manifestaçoes de uma atividade obscura confusa dificilmente acessivel às nossas observações, às vezes denominada por Leibniz por sentimento ou instinto, sem que com isso negue qualquer forma de conhecimento consciëncia ao instinto, apenas que, anda que contusa, pode ser o geme de um conhecimento suscetível de se tomar mais claro e distinto, desde que o sujeito possa realizar uma introspecção, uma reflexão consciente sobre as suas próprias afeições e modificaçoses. Esse procedimento pernite ao homem transitar de inumeros hábitos puramente instintivos originaramente, a um saber consciente, passar do opaco a transparente por uma espécie de cálculo. Mas, é diffcil demarar claranente instinto inteligencia nos anmais superiores e que subsiste no proprio homen. A moral pode não ser capaz de princípios demonstráveis dos quais un dos principais é o de busca do prazer e fuga da tristeza. Essa näo é uma verdade a priori, puramente conhecida pela razäo, pois ela é fundada sobre a experiencia interna ou a partir de conhecimentos confusos, porque näo se pode dizer o que seja prazer ou dor. alegria te tristeza sem experiencia. É uma verdade inata, proveniente do instinto, mas 
กăo por tuma laz namural ou razăo.

Como passar da opacidade das perepcoses confusas que habiam e constituem a matriz passional do tomen. para a ransparencia e precisão de uma ciêneia moral fundirda analogamente sobre os principios da natreza do mondo fisioo? Como justifuar a passagem de um conhecimemo nâ mais que confuso de si mesmo, para determinar os meios de que dispoe para seguir e se elevar gradativamente a ma vida mais perfeita e mas felz? Como Leibniz concilia os principios fúsicos e monais?

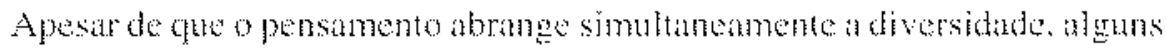
são mas bem distinguidos. Sempre permmece algo do que foi pensado. Nern mo se perde inteiramente, segundo of filosofo o que permite a identidade do individuo en fato de que ofuturo de cadar ser esta ligado aro passado. Náto é preciso a memória nem sempre é fossivel dada a multiplicidade de impressós, mas mesmo assim exerce importante papel.

Anda que inconsciente confusamente sertidas, essats perceptex intersem nos impulsos obscuros que contribuem para nossas aços e deliberaçes. Todas as nossas irresoluços resultam do concurso dessas pequenas percepcoses, hábitos paxöes que intuenciam nossas de liberaços. Impressöes passalas estä na alma no como mas não nos apercebemos enquanto a memoria no for acionada. A "Vontude" submissa a escas pequenas perceposes a essa sensibilidade obscura. chija origem e aça permanecem quase desapercebidss. Agimos por hábio em confomidade com nossas disposiços, mais do gue por una escolha deliberada em plena consciencia de causa. Isso implica que grande parcela da vida humana se apresenta como sersiliva, submissa as les do sentimento e instinto no sentido leibnexiano, ou às do hábito uma espécie de instinto embrionário.

Essa atividade espontânea exerce relevante funçă, porque se fose precisonecorrer à razâo, o que requer tempo hábil e o estorco, isso nos tormaria constantemente falhos.

O hábito e o instinto, atividades. anda que parcialnente inconscientes. suplementam a reflexão consciente, quando necessitrio, e, desabrochamem inteligencia evontade.

Obscura e indistinta na origem. ignorada nagulo do que se tratal a forç ou tendencia se toma sersivel pelos efeitos que ela produz tomando-se manifestir is consciencia segundo sentimento de prazer ou do que ela descobre dependendo da satisfacto ou da contrariedade. O objetivo natural geral da atividade sersivel á a busca do prazer e fuga da dor que näo significa que sejam reamente o maior dos bens. mas porque manifesta madançs adequadas à melhoria da vich Prazer dor resulam do sentimento da consciencia clara ou obscura de perfeç̧̄o ou de inprerfeiçà, incitando à ação. O prazer é um fim natural e tazẩo suficiente dos caforços desenvolvidos na sua busca e preservacto. não dele mesmo. mas ao bem a ele relacionado em que ofun supreno a propria vida, em extensio, intensidade a valor.

Se ha uma afinidade matual entre o homem es outros seres organizatos cm diferentes graus e dotados de sensibilidade e ale mesmo de um certo gra de 


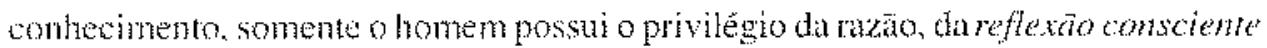
ot de apercepcäo. Ençuanto a percepsão sensitiva e de uma consciencia confusa, a apercep̧ào compöe-se de idejas clatis e distintas sobre a vida interior. O pensamento é o lugar secteto de toda atividade mental, de ordem ideat, bem como dos esforços e da açă a mas especialmente, onde se desenrola a forma superior de vida e se realiza a orden da moralidade. É necessurio conhecer o pensamento definir examente sta natureza intima e determitrar as teis fundamenais, pata compreender como se descruvolve a alividade mental, entender como se pode passar, por esforços conscrentes e disciplinados, a uma vida mas leliz, perfeita e harmoniosa. Assim, somente uma reflexăo consciente pode assegurar uma base sólida às nossas

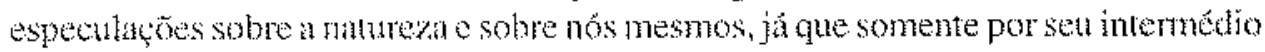
sià acompmhados, ordenados e relacionados os fatos que se sucedem em nossa vida interior, por uma intuiçäo direta, evitando a possibilidade de erro sobre a realidade $e$ sua existênciat. Rarăo ou entendimento é a faculdade de conceber caursas motivos que dão conta da ordenaça e relacionamento dos fatos, suas causas e a construção de um sistema geral onde todos os eventos naturats. fatos da vida interior, idéias. percepcoses açoes se encontran agrupados dentro de uma ordem regular segundo leis constartes e universais, Refhetindo sobre todos os eventos naturais, das leis gue a consciencla on razăo percebe dentro da vida interior encontramos constância e necessidikde, ad menos relativa.

Sem a maāo, agindo unicamente pelo mpirismo, o homem se assemelha aos proprios animais, elevando-se acima destes, quando conseguen ver a ligaçäo entre of fatos, as vertades neessárias a universais. lessa introspeçăo, desse retomo do espirito sobre si mesmo que emerge o combecimentoracional, inteligivel, ac ciencia, qualquer que seju seu objeto. porque á unicamente em nós mesmos que podemas conhecer a realidade a forç substancial da qual hodo é reito. É da consciencia que conlyecemos a realidade as leis determinadas. Ainda que o pensamento surja dos dados da experiencia, de impressöes sensiveis, wo contrário da doutrina sensualista, Leibniz propoe gue hí uma pré-existencia de uma faculdade natural, uma disposiçäo anterior, rażo ou entendimento qué tomado como imato nat alma fumana, capaz de concentrar sua atenção sobre os movimentos a modilicaçoes da vida interior, comparar e relacionar um fito ao outro, de idelas charas e distintas pela eliminaçio dos elementos variaveis e contusos que constituem a percepano sensivel, conferindo-lhes uma significacio e um carater geral.

A razāo é a aptidă uma disposiçă mata que opera sobre os dados primitivos e diretos da consciencia no processo de elaboraçio que tansforma gradativamente o sensivel em concepcoses inteligíveis. A consciencia racional, os princípios que dombinam e regulam todas estas operaços năo derivam de una intuçăo, de uma imediatidade. pois a rază nāo tem sen dominio próprio, mas deriva dos dados diretos da consciencia. É a reflexän, a introspeçāo que condu\% ao teconhecimento da universalidade no sentido que exprimem as lais essenciais tora das quais năo poderia associar suas 
percepções, coordená-las e compreendê-las. A razão, desde o início, tem suas próprias leis, suas exigências naturais e necessárias, mas não precede a consciência distinta, reflexiva. Gradativamete passa a conceber claramente e a formular explicitamente os princípios (luzes naturais, porque são inerentes à natureza do espírito) que a regulam e dirigem suas operações e seus julgamentos, à medida que o espírito encontra em si mesmo a ocasião de aplicá-los à suas percepções. Fugir à autoridade desses princípios é interromper o processo cognitivo.

As leis fundamentais da reflexão consciente se subordinam ao Princípio de Contradição, útil no julgamento do verdadeiro e falso, operando como uma proteção contra a possibilidade de falha do pensamento, mas não contribui para o progresso do conhecimento, apenas aplicado na Matemática, nada informando sobre questões ligadas à existência, à natureza, propriedade dos seres reais e concretos, e ao da Razão Suficiente, porque mesmo que não se conheça a causa, nada ocorre sem uma razão determinante que seja assim e não de outra forma. Para que o julgamento seja inteligível é preciso que se dê uma razão (a priori ou a posteriori), mostrando que a qualidade ou propriedade atribuída ao sujeito está contida dentro da idéia do sujeito, seja explícita, seja implicitamente. Doutrina eminentemente racional em harmonia com o princípio da razão suficiente, tese científica e justificada porque está em acordo com os dados da consciência e da experiência, conforme às exigências de ordem moral, porque sem isolar o homem da natureza ela o eleva pelo privilégio da reflexão consciente à dignidade de pessoa que pode dominar suas ações e destino.

Estreitamente associadas, relacionadas, a vida sensível se compõe de apetite e instinto e a vida intelectual e moral se compõe de razão e vontade, ambas derivadas da finalidade natural, uma dotação interna, que se manifesta mais claramente nos seres organizados e vivos, podendo dar conta da aptidão e inclinações naturais a dirigir os movimentos e atos de acordo com as necessidades e exigências da vida. Instinto é uma disposição espontânea, espécie de conhecimento imperfeito e indistinto, mas eficaz na finalidade de adaptação dos atos a um objetivo. É um direcionador primitivo, e sob este aspecto, princípio inato da atividade moral. O homem, mesmo após o seu nascimento, concepção, pela lei natural da hereditariedade pode receber de uma forma imanente uma espécie de moralidade e que se afirma à medida que a consciência desperta sobre a influência da experiência sensível e da flexão, transformando o que era apenas e tão somente um instinto primitivo em consciência distinta. A vontade, que é a complementação dessas etapas, implica idéia clara e distinta daquela necessidade de adaptação às exigências da vida.

A vontade pode ser definida como uma tendência composta por apercepção (concepção refletida e claramente distinta), embora possa haver apetites ou desejos resultantes de percepções insensíveis. Ações voluntárias são oriundas de alguma reflexão prévia. Assim, vontade é uma propensão natural esclarecida pelo conhecimento relativamente distinto, ainda que de forma confusa ou inconsciente que leva a agir. É o entendimento que introduz a liberdade na vontade e a torna 
espontânea. Isso altera profundamente o significado de instinto vontade. Vontade é $o$ instinto esclarecido pelo entendimento. $O$ instinto se adapta unicamente em virtude de um impulso irresistivel às impressōes e excitações presentes. A imagem, a lembrança de outras impressöes anúlogas se associam e a longo prazo constituem uma especie de experiência que se assemelha ao raciocinio. Mas, difere deste na medida em que fundada sobre uma atraçăo natural, enquanto que o raciocínio implica o conhecimento refletido dos motivos que ligam umas às outras, associadas dentro de um mesmo ato de pensamento. Essa faculdade de discemir as diversas possibilitades que se abrem à nossa atividade, de atribuir um valor relativo, de avaliar a conveniencia dos fins a qual nos inclinamos ou que considemmos desejaveis É que caracteriza a atividade da vontade. Ela se distingue do instinto ou do sentimento porque implica a idéia do bem considerado como fim on como motivo da ação. Vontade é a propensão a agir na proporção do que se objetiva e a ação năo pode prescindir plenanente da vontade pura, parque nossas idétas e julgamentos sugeridos pelo entendimento se misturam as impressöes sensiveis relativamente confusis. Seria um erro considerar vontade e instinto on inclinaçós naturais diferentes de forma absoluta e iredutível. Causas externits e internas determinam a alma certamente, mas näo ntecessariamente, porque não há contradição que a determinação fosse de outra forna. A vontade poderia ser inclinada e não necessariamente. Assim, em Leibniz, a vontade näo é isolada, uma faculdade puramente intelectual de poder autônomo, independente de disposições e propensões naturais, mas está ligada às energias primitivas das quais é um desenvolvimento consciente e adaptaça aos fins claramente conhecidos, deliberadamente aceitos e perseguidos com método e persevenança. Sozinha é uma inclinaçäo natural. Conscientemente reffetida, sabmetida aos ditames da razăo, é um esforço.

Contudo, a razăo näo altera a nattreza intima daquela energia e nem a espontaneidade primitiva é alterada ou dimimuida. A razáo, ao dominar o espirito, liberta a vontade, ao invés de restringíla. À servidăo das paix oes e dos desejos que a subordinam, a razảo se opoe mediante as idéias distintamente conhecidas e hábitos deliberadamente adguiridos. Portano, "nous pouvons dire que nous sommes exempts d'exlavage, en tant que nous agisson avec ane connaissance distincte mais que nous sommes asservis ata pasions, an tant que nos perceptions sont confuses" (Leibriz.1953, p.34).

En suma, Leibniz professa que a vontade se identifica com aquela energia viva e sempre ativa que foma a sabstancia de todo ser otganizado e sensivel e que constitui propriamente sua individualidade. Sob a forma primitiva é uma força que se manifesta dentro do instinto apresentando um sentimento obscuro da finalidade. Esclarecida no homem pela reflexão consciente, por uma disciplina racional e uma energia fortalecida pela consciência distinta dos fins e das ações que conduzem a esses fins.

A vontade é autônoma porque é uma energia submissa a uma lej interna. 
derivada da reflexão e não externa como no instinto dirigido pelo apetite, impressões e excitações sensíveis. A vontade é consciente do poder e dos fins das possibilidades diversas que se oferecem e seu valor relativo. Enquanto o instinto se posta de forma espontânea e quase irresistível na direção do prazer ou mais exatamente para a satisfação imediata das necessidades da vida, a atividade reflexiva do homem, condicionada à sua capacidade de esforço tende à busca do melhor e à perfeiçāo, à conquista dos bens, cuja posse lhe parece como suscetível de proporcionar satisfação mais pura e duradoura. A vida moral surge e se desenvolve à medida que as representações distintas e as indicações da reflexão consciente tendem a se superporem às percepções confusas e às solicitações sensíveis do instinto e do sentimento obscuro da finalidade natural. Razão e sentido coexistem na alma humana e cada uma concorre à determinação da ação e à sua direção geral. Assim, um axioma fundamental da sua doutrina moral é que a razão e a vontade nos conduzem à felicidade, mas o sentimento e o apetite ao prazer. Prazer é um sentimento de perfeição (sem fronteiras ou limites) e dor um sentimento de imperfeiçāo. Quando o prazer é seguido de uma privação (saúde por exemplo) ele encontra seu limite. Sabedoria é a ciência da felicidade e dos meios para conquistá-la. A felicidade é o prazer durável, mais duradoura e pura, persistente, mesmo que a causa tenha desaparecido, estado de sentimento de perfeição. A felicidade é o fim natural e legítimo da açāo esclarecida e dirigida pela razão. Não há uma condenação do prazer ou incompatibilidade com a felicidade. Ambos são manifestações da finalidade espontânea, causados pelo aperfeiçoamento do ser. A coordenação racional do prazer, dos movimentos espontâneos da atividade instintiva o transforma em sentimento de felicidade, mas é a razão que conduz à escolha do melhor.

A busca da felicidade com a vontade submetida à reflexão conduz ao princípio fundamental; que a ação esclarecida e dirigida pela razão não teria outro fím a não ser a progressão contínua de um ideal de vida sempre melhor e mais perfeito.

O prazer, a felicidade surgem como uma sanção dos progressos realizados, da consciência do livre e harmonioso desenvolvimento das faculdades da alma, da satisfação e de suas aspirações, do conhecimento distinto adquirido sobre ela mesma e sobre a natureza e elevado destino que se pode alcançar, utilizando este poder de acordo com as leis da vida e regras formuladas pela retidão da razão. No pensamento de Leibniz a felicidade é o mais elevado grau do instrumental racional, o ápice de perfeição. A busca inteiramente desinteressada do bem ou da perfeição é impossível porque é inconciliável com a aspiração natural, consciente e legítima do ser vivo na direção da satisfação de suas conveniências e aspirações.

A forma mais elevada de prazer, a felicidade, a mais perfeita, está ligada essencialmente à satisfação das exigências normais da vida, mas implica uma coordenação de suas inclinações naturais, uma harmonia racional na alma em conformidade com o julgamento do entendimento, da determinação, das resoluções e das ações voluntárias. Percebe-se no interior desta substituição da decisão racional 
ao impulso espontâneo dos desejos e inclinaçoes naturais, o princípio de uma transformaçăo profunda, de um exercício da vontade refletida, das leis da açăo instintiva, des esforco, de uma escolha que é direcionada pela razão está endereçada ì vontade do melhor do perfeito. Por trás disso um idealismo racionalista.

A vida moral se resume inteiramente dentro da boa vontade firme esincera de agir sempre em vista do mehor, de uma aça exercida para atingir o ideal de uma vida methor, perfeita. a partir de uma ref 7 exöo consciente, aprimonada, à medida que o homem conhece mais distintamente os hins propostos à sta atividade e pode fixar sta escolha segundo a excelencia relativa de cada tim dos objetos. As primeiras manifestacós dessa conkiencia do melhor estí em geme na alma humana, antes mesmo de uma reflexâ mats clara e distinta, sob foma de instinto, percepçoes surdas e quase insensiveis, pequenos impulsos que operam em silencio sem que nos apercebamos que se formam pequenas inclinaçđes à aço dentro da matriz passional. ate porgue estamos em atividade constantemente. Esses pequenos e primeiros thapetites ou desejos" que a matueza nos apresenta nos dirigem mas a prazer que a felicidade. pois é mais importante o prestente para thomem. A razào e a experiencia moderam essas manilestações inferrores, nmo a um prazer de mator longevidade; a felicidade.

Pari o despertar e desenvolvimento de uma vida moral em nós, a reflexäo consciente é indispensávele sem "boa vontade" ou esforço que possibilite o acesso to melhor a perfeiçāo, como o instinto fos leva ao prazer, não poderiamos dominar completamente nossos desejos e preferir um bern futuro em troca de um bem ou sat isfaçuo presente. Ençunto os pensamentos confusos seguidamente se apresentam claramente, os pensamentos distintos, säo distintos apenas potencialmente. Para atualizár los é preciso atençäo permanente. A negligencia e a brevidade do tempo ajudam a opor as pahvras e imagen claras aos sentimentos mais vivos. Mas, o homem tem poderes para alterar esta sitnaçăo e firmar a observância.

En auxilio temos a educaço, a Graça Divina, doadoras da luz necessária para uma resoluçäo celfaz a a seguir, a luz da razäo, a constrair um império da razāo sobre as paixöes, sobre as inclinaços insensiveis, tornatzo a virtude agradavel e natural. Vida moral s a vida racional que tem por fim a felicidade, mesmo que sacrificando aquilo que presentemente é aparentemente um bem. Ainda que não seja mestre da sun vontade de maneiri direta, e o homem É causa disso porque não escolhe as açoes pelia vontade, temos um certo poder ainda sobre a vontade, porque podenos contribuir indiretamente a desejar uma outra no lagar desta presente. medinte a anexaçăo da inteligencha ì espontaneidade.

A evoluçăo da vida moral inplica o desenvol vimento de uma consciência pelo hábito da reflexão, aplicada à considertoño dos fins on dos motivos da ação e a renfirmaçăo da vontade aplicada metodicamente à jatica de esforços sempre renovalos por causa dos apetites, paxóes e representaçōes confusas. 1sso nada mais edo que o discernimento que o homem pode aplicat à aquisiça de uma forç pessoal de resisténcia aos impulsos cegos do instinto ou das paixóes e se proteger das 
inclinaçơs sensíveis. A funçäo essencial da vontade (pelo hábito) é a de suspender a decisüo à qual se inclinam, a princípio, as tendências naturais para assegurar e permitir ao espírito a escolha dos meios de recuperar o domínio de si mesmo e elevar-se acima dos tumbltos das impressoes sensiveis. Pode-se fazer o que a vontade e a razāo ordenam por método e por artifício (substitução de um vício por uma diversāo). A boa vontade é um instrumento de frenagem da impetuosidade das tendências naturais, mas somente a perseveranç 2 a ordem permitem a manutençāo ou preservação do imperio da razão. Na vida moral, na procura do bem e o escôo pela busca da perfeiçắo năo está nem tanto no bem julgar quanto a ocasião de uma sincera boa vontade. A virtude como a felicidade e fiuto natural e a recompensa que anima o desejo sincero e durível de as adquirir. Portanto, é preciso menos ciência do que boa vontade para a aquisiçño da verdade ira felicidade.

O otimismo de Lecibniz, sem menosprezar a falibilidade de uma natureza imperfeita s limitada, tem plena confiança ma retidäo da razăo energias da vontade, em um futuro promissor. Em una passagem da Teodicéa, afirma: "le gyenre humain. par-vienne avec le temps à unc plas grande perfection que celle que nous pounons nous imaginer preschtemem". (op. cit. 1953, p.19)

Ser moral depende de ser tacional, poder escolher dentre os fins, os melhores, aqueles que asseguram bem. a perfeiçăo a felicidade. lsso implica cm liberdade, live arbítrio. Como isso se concilia com a questăo do deterninismo universal, condiçáco fundamental de toda afimaçono relativa à ordem dos fenomenos naturais às leis gerais e constantes que regulam o Universo? Segundo Leibniz, trata-se de um equivoco a contradiçäo á apenas aparente. O princípio de Razão Suficionte garante que todo evento no Universo tenha uma causa e pode-se explicar a priori porque é assim e năo de outra loma. A natureza é submissa a um determinisno cuja necessidade a razăo, conservando-se à ciéncia a formulaçäo das leis e, à experiência, a verificação permanente.

Como as açóes estato condicionadas pela intervençäo do pensamento e da vontade humana devem encontrar iguałmente explicaçăo, sua razăo de ser em alguma causa jú subsistente. Uma reflexia consciente pretende uma ordem ideal, mas que mão escapa à lei universal do determinimo. Leibniz rejeita qualquer possibilidade de um poder volumário, ditado arbitrarianente que induz à açāo, sem uma determinação causal. A liberdade humana näo ś simonimo de uma "indiferenga de equilibrio" como se houvesse uma inclinaço para a açio da classe; tanlo faz como tanto fez, de um sim on um nảo, dentro de ama gama de alternativas. Podemos ignorar a causa, mas quando optamos, optamos por algum motivo, mesmo que desconhecido, "tout

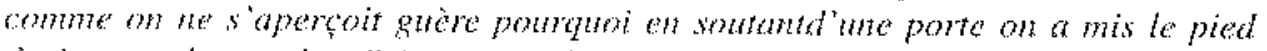
droit avant le guache..." (op cit, 1953, p.24)

A libertaçäo da vontade, das inclinaçöes ou apetites naturais mäo implica que efa esteja isenta da lei ou da necessidade natural ou causalidade. Há uma tentativa de associar a açăo de forças físicas que delerminam a sucessăo mecânica dos eventos 
naturais à açăo ideal de uma fanalidada claramente conhecida dentro da rellexăo consciente. A causalidade na esfefa moral vem completar a causalidade do plano físico subordinadas à lei universal A refexăo conseiente é uma força que se associa e ampia a lei universal da causalidade, a lei superior que rege a ordem ideal da finalidade ou lei da commentencia. Isso nào equivale a dizer que esse novo fator possa de algurma forma isentar a vontade do homem do determinismo universal das causas eficientes que regem, por relaçöes fixas e invariáveis, a engrenagem mecanicista dos fenômenos, até porcue o homem extá inserido nessa natureza.

Ao contrário, a que temos agora é um novo deterninismo, o do plano ideal. moral e consciente, fundado sobre o conhecimento distinto da finaliclade. O espirito reconhece possibilidades futuras, o que permite a escolha e adaptação dos meios ot atos às possibilidades julgadas melhores, conforme as necessidades e conveniências. A partir disso, ama lei ordena os esforços, adaptados às conveniencias do mecanicismo, de maneira a assegurar a conquista progressiva da realizą̧a do fim objetivado. Determinismo mental da finalidade e da natureza têm funç̧ăo distinta, mas há uma ligaçăo natural e constante entre as operaçōes da vida mental e os movimentos que se sucedem no organismo da natureza. No entanto, Leibniz rejeita a pretensa antinomia entre deterninismo e liberdade hmana. Como a indiferença uma imperfeiça (ausência de conhecinento) a ciência e a bondade seriam inúteis e reduzidas ao acaso. Uma acăo é mais lonvável quando encerra boas qualidades.

Leibniz liga ciencia natural e moral em um só elo lógico e direto; a razăo. 0 hato de gue a vontade do homem é livre e autônoma năo decorre de uma violaçăo das leis naturais, por una derogaçäo inexplicável ao determinismo universal, mas em decortência das leis deste determinismo. Assim, nada há sem razăo e embora a razão incline, não necessita, ou seja produz uma tendêtnca e não uma necessidade. A liberdade da indiferençá impossive e nociva, porque ela nāo convém nem mesmo ao Criador, pois é deterninado a fazer o melhor e as criaturas sempre deteminadas, por consegüencia, por azöes internas e extertas. Mais perfeito o espirito, quanto mais infernamente estiver o princípio e a razão da saa determinaçáo.

Assim, a triade espentancidade, contingência e intelighncia, isto है. entendimento on reflexäo consciente forma a liberdade do homem. Mas, deteminaçăo e necessidade são coisas distintas. Se houvesse perfeito conhecimento de todas as circunstancias externas e internas a homem, certamente os pensamentos serim determinados tanto quanto os movimentos e todo ato live seria necessário.

Na Matemática e na Geometria há necessidade, nas na Fisica como na Motal há tendência sem necessidade. A questão é saber se à influência deferminante dos molivos pode se conciliar com a crença na liberdade de um poder voluntärio. Que as açôes voluntárias sejam determimadas, não implica necessidade e nāo se opöe à espontaneidade. Foŗ̧as naturais não sảo inconciłáveis com liberdade de vontade, porque os objetos não influenciam as substâncias intelígentes como causa eficiente e fisica, mas como causas finais e morais. 
O homem é livre, tem o domínio de si mesmo, ainda que os fins que inclinam (internamente) sua vontade não sejam necessários, pois estão sujeitos ao seu assentimento, na dependência de serem más ou boas. A liberdade se afirma no assentimento, na submissão refletida da vontade à razão.

Por sua vez, a necessidade não pode ser evitada, ao contrário da moralidade, e torna inútil toda oposição. O que é natural depende da conveniência das coisas e o que é necessário é essencial e imutável. Neste sentido é que o crime é natural sem ser necessário. Enquanto o movimento dos corpos pode ser explicado por causas eficientes, as percepções distintas da alma onde há liberdade se explicam por causas finais.

Uma ação é natural porque tem origem e sua razão de ser dentro das próprias disposições ou propensōes inerentes ao indivíduo, e por isso não pode ser necessária. Pode-se dizer que uma ação é livre quando precedida de uma deliberação, de uma reflexão sobre os motivos que a solicitam e que inclinam a vontade, portanto um objeto de escolha, de uma adesão consciente, revestindo a determinação de um caráter pessoal e autônomo. Liberdade é uma espontaneidade natural esclarecida pela inteligência, enquanto a necessidade suprime toda deliberação.

A liberdade do espírito, oposta à necessidade com relação à vontade é o livrearbítrio. Ainda que o entendimento dirija a vontade, não impede que ela seja contingente e não confere uma necessidade absoluta ou metafísica. Assim, 'c'est dans ce sens que j'ai coutume de dire que l'entendement peut déterminer la volonté suivant la prévalence des perceptions et raisons, d'une manière qui, lors même qu'elle est certaine et infaillible, incline sans nécessiter" (Leibniz, 1945, p.57).

Portanto, a vontade não é inteiramente e absolutamente livre, mas relativa e limitada, porque existem disposições hereditárias, uma pré formação, apetites exigidos pela vida orgânica. No entanto, está em poder do homem a capacidade, pela reflexão consciente, de expandir indefinidamente sua liberdade, exercitando e se habituando a não agir, exceto em pleno conhecimento de causa.

A necessidade que caracteriza o instinto é de uma ordem diferente da vontade. Enquanto o instinto obedece a uma necessidade da natureza, sobre a qual há apenas uma consciência obscura, a vontade a uma necessidade da razão, cujo conhecimento é relativamente distinto e deliberadamente aceito.

Essa necessidade moral que deriva da livre escolha, a partir da reflexão, se relaciona às causas finais. Essa necessidade moral dá origem ao sentimento de obrigação. O princípio de conveniência postula que há diferença entre o que é absolutamente necessário e o que é determinado pela razão do melhor.

Assim, para o homem honesto, a necessidade de agir em busca do melhor adquire uma força igual à necessidade natural, porque não concebe a possibilidade de fazer o que seria contrário à virtude, o que torna a obrigação moral algo que não é exógeno ao homem, mas endógeno, porque emerge da reflexão. Como a obrigação é uma necessidade moral endogenizada, uma vontade livre ou autônoma não poderia ser um poder independente de toda determinação, mas um poder que se auto determina 
e deve ser cracontrado intermanente no homem, vial reflexão, que as forna indissociáneis. É essa capacidide de retlexāo que toma liberdade e obrigaçăo endogenas resulado da ordem e da disciplina que a razão impöe contra as tendencias primilivas.

Pelo fato de ter consciência de uma ordem de excelência e de perfeçça, dentre as varios bens que the solicitam, o homem é capaz de fugir da servidĩo que as impressôs sensiveis, instintos a apetites pesam sobre a vida puramente animal. É. desiva foma que ele se toma live autônomo.

A consciencia desse poder o laz se determinar en contormidade com una ordem ideal em busca do mehor a a se esforçar na direça do berm. Pela livre escolha, pela adesào da vontade, isto e do indivíduo considerado dentro da energin que constitui sua substancia e dentro da realidade concreta e viva gue o bem se toma verdade iramente monal. De onde surge a necessidade?

A razăo transfoma em lei, em necessidade, a regra monal. Mas, existe uma diferenca anre a necessidade ideal ou lógica (absoluta, restria, intlexivel e nāo hí liberdade ascolha) do julganento pelo qual o espirito reconhece af irma que um bem ś superior a outro. eque racional a escolha, e a necessidade moral relativa porque ao paswar do julgameno à resolugäo que leva à ação, ohomem tem consciencia de poder que anda conserva de se desviar desta resolução, porque a resoluçăo plena e eficaz da vontade reclama comra o julgamento a adesảo pessoal com toda a sua energia on de conveniencia que se impöe à vontade e transforma em le aquilo que nato ara mais do que trma regra denl.

Assim, a necessidade moral náo enenos soberana e universal do que a ideal, e mesmoque o ind viduo recuse a ta se subneter, näo ignona que ela se impōe como uma lei suprema de uma vida racional, gue violando, deliberadamente, comele uma falta, um atentado il ordem unisersal.

A consciencia desta espécie de necessidade superior às contingências da vida

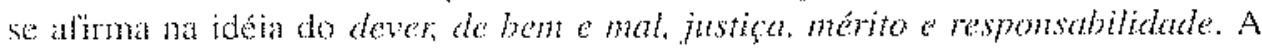
finalidade natural, sensivel em suas fomas elementares e primitivas, se toma inteligivel pela intervenço da razăo se transforma em monal pela subordinaçăo das inclinações do homem a uma lei tuiversal de ordeme de hamonia. E por uma necessidade moral subordinada ao principio da Razu Suficiente que o mais sábio se sente obrigado à escotha do melhor. Fortanto, é uma imperleyano de nossa liberdade quando escolhenos o mal no lugar do bem, enganados pelas aparencias. Necessidade e dever são a mesma coisa para o Sábio.

A razä conduz ao confecimento da necessidade moral a consciencia do dever, mas näo se comtrapoe à doutrina do sentimento de obrigaçióo emanado da auroridade da Vontade Bivina. Contudo. Leibniz não aceita a objeção de que a idéia do dever parece implicar o reconhecimento de uma autoridade soberana, cujos mandamertos se impöen à conseisucia e is vontade do homem, sem a qual, o devere a obriguçăo permaneceriam ideais e sem o canter imperativo e busca uma concilaçăo. 
Seu espírito concebe perfeitamente a coexistência de uma lei moral, onde bem e melhor se confundem com a lei divina e não separa a ciência moral da teologia. A fonte primeira da necessidade moral, como de todas as verdades, é o entendimento e a vontade de Deus. A consciência da obrigação moral está subordinada à Vontade Divina, que tem por essência o objetivo do soberano bem.

A escolha do melhor, do bem, se impõe universal e soberanamente a toda vontade consciente, porque Deus quer livre e necessariamente o soberano bem, sem restrições ou servidão. No entanto a determinação do bem e do mal, o que é permitido ou condenado, não pode depender da decisão arbitrária da vontade de Deus, mas de seu entendimento que conhece toda verdade e toda conveniência, a qualidade e o valor das intenções das ações. A virtude existe antes do homem ser criado. A questão é saber se o homem agiria na direção do melhor sem apelar para a autoridade Divina. Segundo Leibniz, se não houvesse Deus que não punisse ou recompensasse, os preceitos e obrigações seriam dispensáveis. Aparentemente isso contradiz uma outra passagem onde afirma que o dever e a lei do bem maior se impõem soberanamente à vontade racional, mesmo que Deus não formulasse expressamente seus mandamentos. Aparentemente apenas, porque reconhece que certas obrigações seriam dificilmente aceitas pelo homem, em razão das falhas de sua inteligência e mais ainda de sua vontade. Mas, isso se aplica não à consciência da obrigação, mas à ação que ela é sucetível de exercer sobre a vontade imperfeita do homem. É sobre o ponto de vista prático para assegurar a vitória da consciência moral sobre os atrativos das satisfações sensíveis que julga útil apelar para a idéia de um mandamento divino, pelos receios e esperanças que essa idéia sugere. Os nossos erros não derivam de nossas paixões negativas, de nossa maldade, mas da nossa ignorância.

"Perdoai-os SENHOR, eles não sabem o que fazem" pode ter este significado: não somos maus, somos ignorantes antes de tudo.

\begin{abstract}
:
The reason and the wish to drive the happiness. Leibnitz teach a rational idealism, stamping a conscient reflexion about intentions and laws of a rational life. The happiness can't dispensewithto the instrument of reason. The moral law want that the man execute his work to be intelligent and free, following the reason. The moral conscient is a expression of the a rational judge that drive the actions. Second Leibnitz, the reason of ours actions is in ourself and only the man had a conscient reflexion.

The reason to controll the spirit, liberate the desire, instead of limit it. Leibnitz teach that the desire identified with that live energy and active that form the substance all of organized creatures, to form your individually. The moral creature depends of your irrational entite, sellecting the best ends to reach the perfection and the happiness. This's implicate in freedom, free resolution. To Leibnitz the desire of man is free and autonomy, don't violate the natural laws, following, therefore, a universal determinism. Through, the liberty justified in submission reflects on desire of a reason.
\end{abstract}


Keywords:

Goodness, action, moral, reason, desire, law, freedom, happiness, reflexion.

Referências bibliográfĭcas:

ARISTÓTELES. Tópicos. Säo Paulo: Abril, 1987.(Os pensadores, v.4).

BELAVAL, Yvon. Leibniz: Initiation a sa philosophie, Paris: Librarire Philosophicue, 1962.

CHEVALLIER, L. La Philosofie de Leibniz. Paris: Pres.U. France, 1968.

COUTURAT, L. La Logique de Leibniz. Paris: S. Germain, 1951.

DESCARTES, Rene. Discurso do método. São Paulo: Abril, 1983. (Os pensadores, v.15).

ESPINOZA. Baruch de, Pensamentos metafísicos. São Patulo: Abril, 1987.(Os pensadores,, 177 .

JALAMBERT, D. Le Dieu de Leibniz - Dijon: Univ, Press, 1984.

LEIBNIZ, Gottried Wilhelm. Discurso de Metafisica. Paris: Aulbier Montaigne, 1945.

Cartas à Arnould. Paris: Aubier Montaigne, 1966.

Monadologia. Parts: Aulbier Montaigne, 1958.

Monadologia Säo Paulo: Abril, 1988.(Os pensadores, v. 19).

Teodicéia. Paris: Aulbier Montaigne, 1953.

. Novos Ensaios. Paris: Aulbier Montaigne, 1970.

MOUREAU, J. LUniverse Leibniziene. Paris: Univ.Press, 1990.

PASCAL, Blaise. Pensamentos. São Paulo: Abril, 1986.(Os pensadores, v.16). 